\title{
Sliding Modes for a Manipulator Arm of 4 Degrees of Freedom
}

\author{
https://doi.org/10.3991/ijoe.v13i10.7498
}

Angie J Valencia C, Óscar F. Avilés, Mauricio F. Mauledoux

Militar Nueva Granada University, Bogotá, Colombia

u1801843@unimilitar.edu.co

\begin{abstract}
The first step in designing a controller for a manipulating arm is to determine its configuration, which means, analyzing the main components that make up the mechanism. A manipulating arm is composed of joints, motors, sensors and other elements, which are linked to conform the different degrees of freedom (generalized coordinates: prismatic, rotational or a combination of both, which is presented as the most unusual), which allow the calculation of the dynamic model implemented to obtain the control specifications [1]. In this paper, the calculation of a controller by sliding modes for a manipulator arm with 4 rotational degrees of freedom will be done, showing the respective results and conclusions at the end.
\end{abstract}

Keywords-Arm Manipulator, Articulated Pair, Degrees of freedom, Dynamic Model, Generalized Coordinates, Sliding Modes Controller

\begin{tabular}{lc}
\hline \hline & Nomenclature \\
\hline Degrees of freedom & DOF \\
Derivative of error & $e$ \\
Double derivative of error & $\dot{e}$ \\
Electrical Motor Constant & $K_{e}$ \\
Error & $e$ \\
Generalize Coordinates & $q$ \\
Generalize Coordinates of Acceleration & $\ddot{q}$ \\
Generalize Coordinates of Speed & $\dot{q}$ \\
Gravitational Forces Vector & $G(q)$ \\
Inertial matrices & $M(q)$ \\
Vector of centrifugal and Coriolis forces & $V(q, \dot{q})$ \\
Vector Friction Forces & $B(\dot{q})$ \\
\hline \hline
\end{tabular}

\section{$1 \quad$ Introduction}

The physical composition of a manipulating arm is similar to the anatomy of a human arm, so that, on certain occasions, the elements which constitute it are referenced using terms such as hip, shoulder, elbow, and wrist. A manipulator is defined as a set 
of rigid bodies interconnected by prismatic or rotational junctions which generate relative movements of the elements that constitute it, producing displacements in the final link of the kinematic chain [1]. These mechanisms are implemented for risky applications that have an may have a negative impact on human health, so the importance of designing control algorithms for their functioning is evidenced [2].

For the design of the controller, it is necessary to obtain the kinematic and dynamic models that define the behavior of the mechanism's movement. The kinematic model describes the Cartesian space of the articulated trajectories located at the end of the open kinematic chain and is defined as the study base of the dynamics in which the actual forces in that system are considered [3,4 ]. Therefore, a dynamic model is calculated to analyze the necessary forces to cause movement. In other words, the torque required to manipulate the position and velocity variables in the hybrid platform [5].

This work is organized as follows: Section 1 describes the physical characteristics of the mechanism to be implemented, as well as the model that defines the required torque by each of the joints, in addition to the required speed behavior for the motor's movement. In section 2 , the results of the controller development by the sliding mode method are presented. Section 3 presents the conclusions of the study.

\section{Manipulator Structure}

Figure 1 shows the configuration of the manipulator to be implemented, where a 4 DOF arm is described. It should be noted that the center of mass for the links is located in the middle of each one of them.

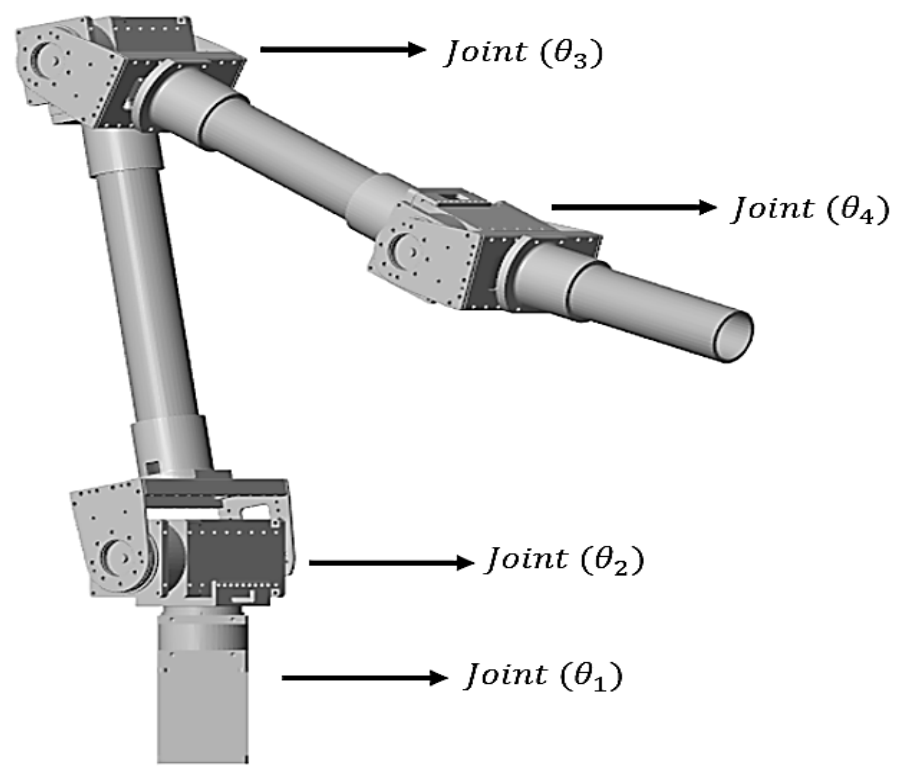

Fig. 1. Four DOF Manipulator Arm. 


\subsection{Inverse Dynamics of manipulators}

After specifying the manipulating arm's configuration, the lagrange formulation of equation (1) is implemented, which determines the dynamic model for the calculation of the torque to be controlled in each one of the links, taking into account its mass, length, inertia, viscous friction and gravitational force [6].

$$
\tau=M(q) \ddot{q}+V(q, \dot{q})+G(q)+B(\dot{q})
$$

For ease of implementation, the dynamic model must be expressed as shown in equation (2), in order to obtain a more adequate configuration when calculating and simulating the controller to be designed.

$$
\left[\begin{array}{c}
\tau_{1} \\
\tau_{2} \\
\tau_{3} \\
\tau_{4}
\end{array}\right]=\left[\begin{array}{cccc}
A & B & C & D \\
E & F & G & H \\
I & J & K & L \\
M & N & O & P
\end{array}\right]\left[\begin{array}{c}
\ddot{\theta}_{1} \\
\ddot{\theta_{2}} \\
\ddot{\theta_{3}} \\
\ddot{\theta_{4}}
\end{array}\right]+\left[\begin{array}{c}
Q \\
R \\
S \\
T
\end{array}\right]+\left[\begin{array}{c}
U \\
V \\
W \\
X
\end{array}\right]+\left[\begin{array}{cccc}
v_{1} & 0 & 0 & 0 \\
0 & v_{2} & 0 & 0 \\
0 & 0 & v_{3} & 0 \\
0 & 0 & 0 & v_{4}
\end{array}\right]+\left[\begin{array}{c}
\dot{\theta_{1}} \\
\dot{\theta_{2}} \\
\dot{\theta_{3}} \\
\dot{\theta_{4}}
\end{array}\right]
$$

\subsection{Motor Specifications}

To obtain the necessary variables for the controller design, speed and torque specifications given by the Dynamixel Pro M54-60-S250-R motors in Figure 2, which will be located in each of the mechanism's DOF, must be considered. From there, it is obtained that the motor's top speed is 28.8 RPM, so that in figure 3, the system's most efficient torque is determined and thus, the control variable's saturation is defined.

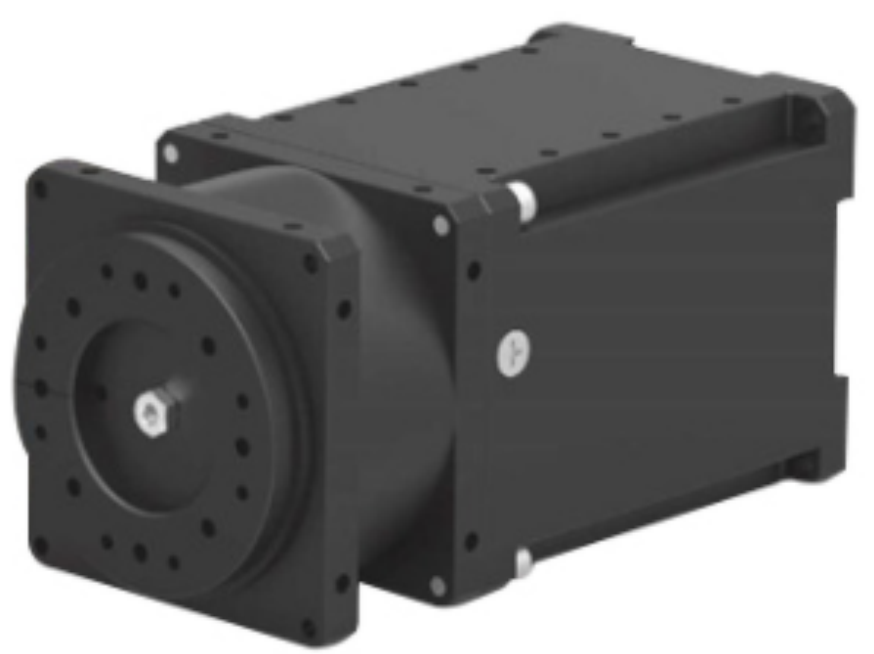

Fig. 2. Dynamixel Pro M54-60-S250-R 


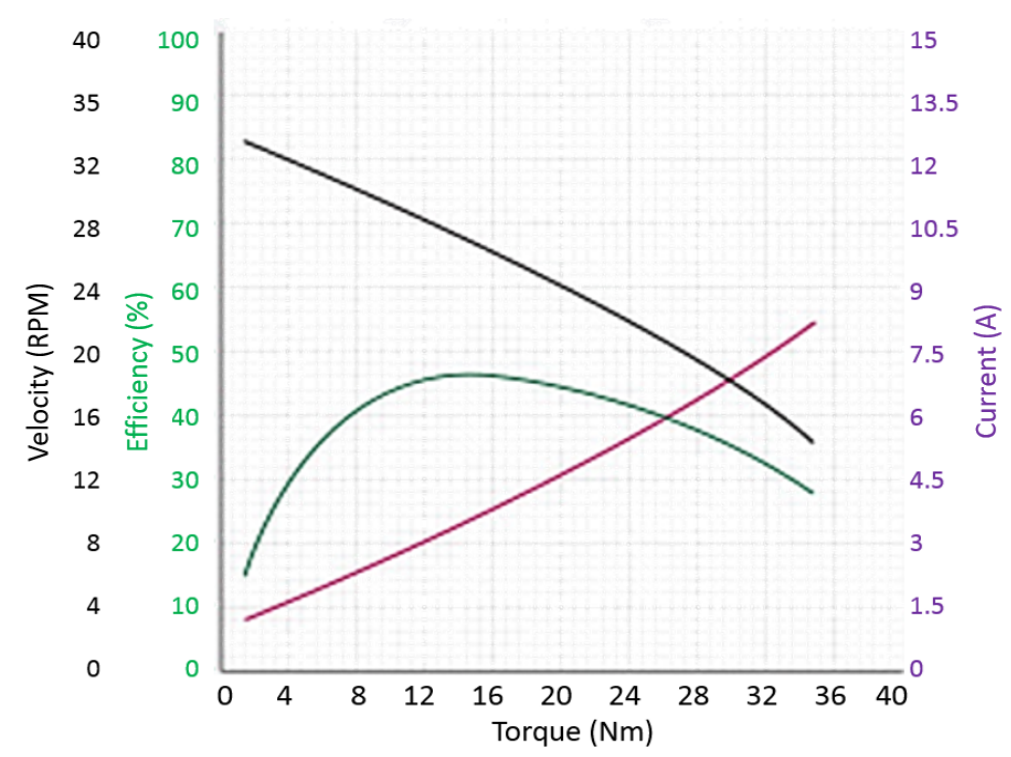

Fig. 3. Velocity, efficiency and current vs. Torque plots

\subsection{Sliding Mode Controller}

The sliding modes controller's principle consists in designing a sliding surface, responsible for forcing the system's variables so that their behavior resembles such surface. Then, the dynamic system's control law is determined by the sliding surface equation in (8) and its derivative in (9) [7]. It is necessary to take into account that $\dot{e}=\dot{e}(t)=\frac{d e(t)}{d t}$. The same concept will be considered for the generalized coordinates $(q)$

$$
\begin{gathered}
\sigma=\dot{e}+k_{v} e+k_{p} \int e d t \\
\dot{\sigma}=\ddot{e}+k_{v} \dot{e}+k_{p} e
\end{gathered}
$$

After defining the sliding surface, it is important to ensure the existence of the sliding surface itself. For this, it is taken into account that the states of the system slide on the surface without being affected by parametric variations or external perturbations [8].

To obtain the control law, equation (1), which determines the dynamics of the manipulator, is retaken up with its control variable $\ddot{q}$ as shown in (10).

$$
\ddot{q}=\frac{\tau}{M(q)}-\frac{V(q, \dot{q})}{M(q)} \dot{q}-\frac{G(q)}{M(q)}-\frac{B(\dot{q})}{M(q)}
$$

Equations (11) to (19) show the solution required to obtain the final control law described in equation (20), where $\dot{\sigma}$ in equation (12) equals 0 . 


$$
\begin{gathered}
\ddot{e}=\ddot{q}_{d}-\ddot{q} \\
\dot{\sigma}=\ddot{q}_{d}-\frac{\tau}{M(q)}+\frac{V(q, \dot{q})}{M(q)} \dot{q}+\frac{G(q)}{M(q)}+\frac{B(\dot{q})}{M(q)}+K_{v} \dot{e}+k_{p} e \\
\tau_{e q}=V(q, \dot{q}) \dot{q}+G(q)+B(\dot{q})+M(q)\left[\ddot{q}_{d}+K_{v} \dot{e}+k_{p} e\right] \\
\dot{\sigma}=\ddot{q}_{d}-\frac{\tau_{e q}+\tau_{N}}{M(q)}+\frac{V(q, \dot{q})}{M(q)} \dot{q}+\frac{G(q)}{M(q)}+\frac{B(\dot{q})}{M(q)}+K_{v} \dot{e}+k_{p} e \\
\tau_{N}=\left\{\begin{array}{cc}
-L \operatorname{sgn}(\sigma), \quad & \sigma(x) \neq 0 \\
0 \quad, \quad \sigma(x)=0
\end{array}\right. \\
\dot{\sigma}=\ddot{q}_{d}-\frac{V(q, \dot{q}) \dot{q}+G(q)+B(\dot{q})+M(q)\left[\ddot{q}_{d}+K_{v} \dot{e}+k_{p} e\right]+\tau_{N}}{M(q)}+\frac{V(q, \dot{q})}{M(q)} \dot{q}+\frac{G(q)}{M(q)} \\
+\frac{B(\dot{q})}{M(q)}+K_{v} \dot{e}+k_{p} e \\
\dot{\sigma}=-\frac{\tau_{N}}{M(q)} \\
L \cdot \operatorname{sgn}(\sigma)=\frac{\tau_{N}}{M(q)} \\
M(q) \cdot L \operatorname{sgn}(\sigma)=\tau_{N} \\
\tau=V(q, \dot{q})+G(q)+B(\dot{q}) \\
+M(q)\left[\ddot{q}_{d}+K_{v} \dot{e}+k_{p} e+L \operatorname{sgn}\left(\dot{e}+k_{v} e+k_{p} \int e d t\right)\right]
\end{gathered}
$$

\subsection{Controller Parameters}

For the calculation of the controller, we propose as $k_{p}$ simulation constants, those arranged in equation (25) and $k_{v}$, those arranged in equation (26); obtained from the definition of a second order Ruth polynomy with a damping coefficient $\xi=0.9$ and a sampling time of $0.15,0.17,0.13$, and 0.05 for the four joints, respectively. The sampling time variation is defined to eliminate the error generated by the sum of the accumulated inertial effects in each of the joints of the kinematic chain.

$$
k_{p}=\left[\begin{array}{cccc}
163.653 & 0 & 0 & 0 \\
0 & 905.958 & 0 & 0 \\
0 & 0 & 1549.243 & 0 \\
0 & 0 & 0 & 10472.885
\end{array}\right], k_{v}=\left[\begin{array}{cccc}
61.402 & 0 & 0 & 0 \\
0 & 54.178 & 0 & 0 \\
0 & 0 & 70.848 & 0 \\
0 & 0 & 0 & 184.206
\end{array}\right]
$$

\section{$3 \quad$ Analysis of Results and Discussion}

To verify the controller's operation, random paths that ensure that the mechanism passes through its center of rotation are presented. In figures 4 through 7 , the behaviors generated by the sliding modes controller are obtained. In them, the blue signal shows the desired behavior and the violet signal shows the obtained behavior.

Then, the speed behavior generated by the controller in Figures (8) to (11) is obtained with the same signals as those used for the position behavior. 


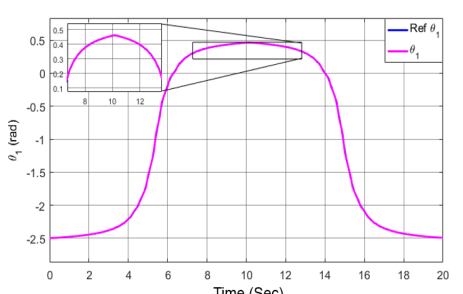

Fig. 4. Sliding Mode Control in joint 1

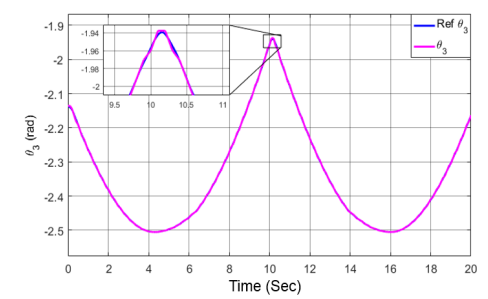

Fig. 6. Sliding Mode Control in joint 3

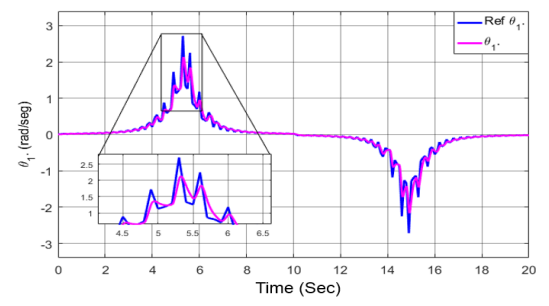

Fig. 8. Sliding Mode speed in joint 1

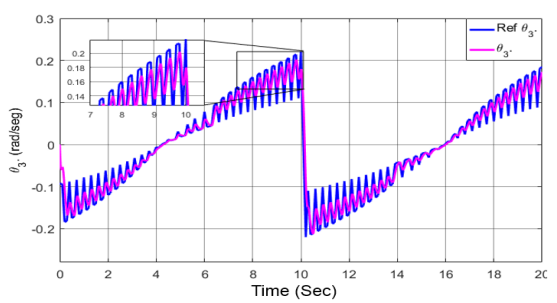

Fig. 10.Sliding Mode speed in joint 3

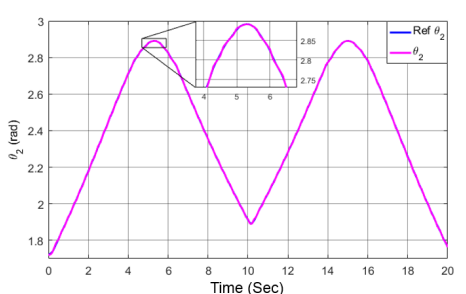

Fig. 5. Sliding Mode Control in joint 2

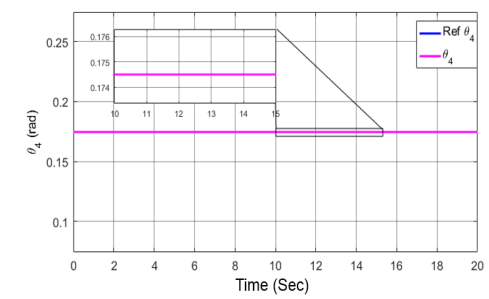

Fig. 7. Sliding Mode Control in joint 4

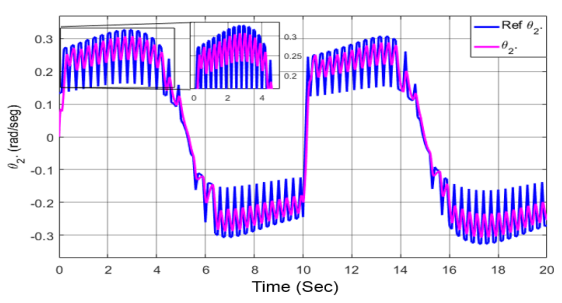

Fig. 9. Sliding Mode speed in joint 2

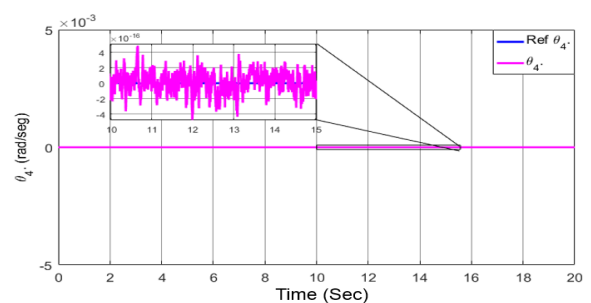

Fig. 11.Sliding Mode speed in joint 4

\subsection{Error analysis}

After obtaining the behavior in position and speed, the calculation of errors generated in each of the joints is dona. The errors produced by the sliding modes controller are described in Figure (12) and (13). 

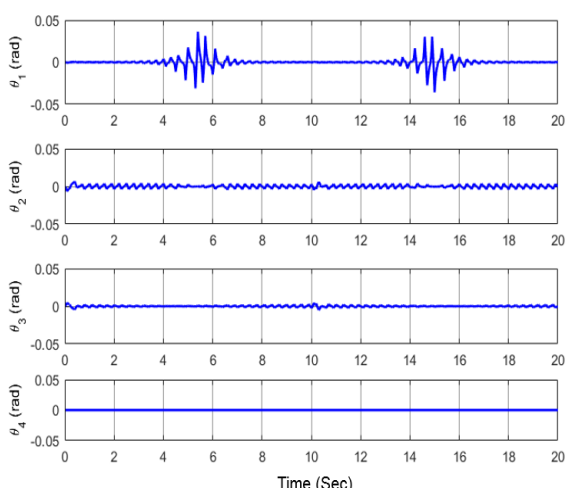

Fig. 12.Sliding Mode Position Error
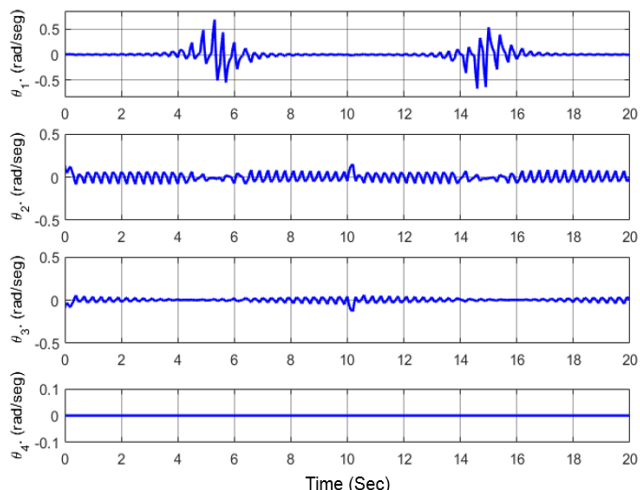

iime (Sec)

Fig. 13.Sliding Mode speed Error

A numerical analysis is made, using the mean square error formulation, since it incorporates the estimation variance, as shown in table 1 .

Then, the power required by the controller to cause the previously defined movements is calculated. In figure (14), the required power by each joint is observed, while in figure (15) its energy is obtained.

Finally, Table 2 shows the numerical values for the maximum power required by each joint

Table 1. Sliding Mode Joint errors

\begin{tabular}{|c|c|c|}
\hline Joint & Mse Position & Mse Speed \\
\hline 1 & 0,8591 & 19,0019 \\
\hline 2 & 0,3462 & 7,5928 \\
\hline 3 & 0,1768 & 3,8629 \\
\hline 4 & 0 & 0 \\
\hline
\end{tabular}
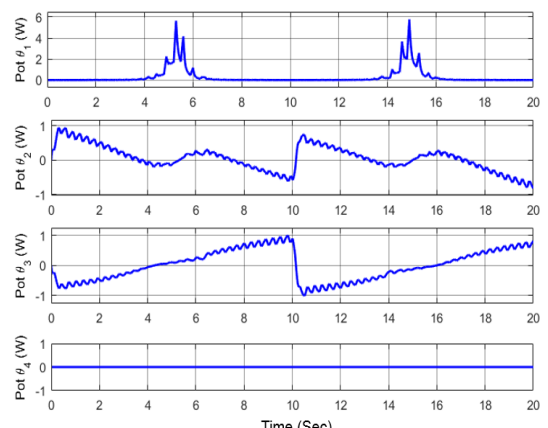

Fig. 14.Sliding mode power

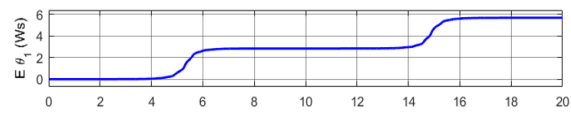

$\sum^{0}{ }^{6}$
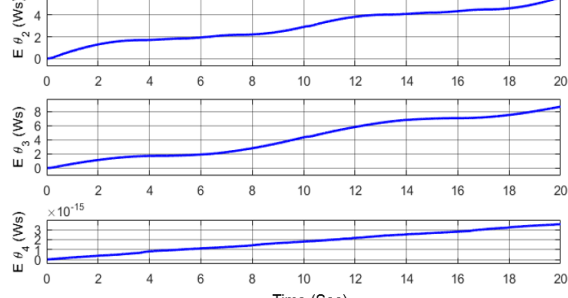

Time (Sec)

Fig. 15.Sliding mode consumption 
Table 2. Sliding mode power consumption

\begin{tabular}{|c|c|}
\hline Joint & Power Consumption (W.s) \\
\hline 1 & 5,682 \\
\hline 2 & 5,638 \\
\hline 3 & 8,702 \\
\hline 4 & 0 \\
\hline
\end{tabular}

\section{Conclusions}

The previously obtained results indicate that the sliding mode controller shows tolerated behavior for precision applications, since the errors are not minimal with values of 0.8591 for articulation 1, 0.3462 for articulation 2, 0.1768 for articulation 3 and 0 for articulation 4 . The above shows that the best trajectories are obtained when the control law is applied directly on the dynamic model of the system, that is, on the inertia, cetrifugal force, coriolis and friction matrix arrays.

For speed, we obtain errors of 19.0019 for articulation 1, 7.5928 for articulation 2, 3.8629 for articulation 3 , and 0 for articulation 4 , with a minimum of power required as observed in Table 2.

\section{$5 \quad$ Acknowledgment}

The research for this paper was supported by Nueva Granada Military University, through the project ING-IMP-2138

\section{References}

[1] L. F. L. Apostolovich, "Modelación y Simulación Dinamica de un Brazo Robótico de 4 Grados de Libertad para Tareas sobre un Plano Horizontal.," Tesis para optar por el titulo de Ingeniero, Pontificia Universidad Católica del Perú, Facultad de Ciencias e Ingeniería, Lima, Peru, 2009.

[2] I. Bambino, "Una introducción a los robots móviles," 2008.

[3] J. J. Yague Niño, "Control Automático de un Brazo Robot de 5 Grados de Libertad con Arduino," Tesis para optar por el titulo de Ingeniero, Universidad de Valladolid, Ingeniería Técnica de Telecomunicaciones, Especialidad Sistemas Electrónicos, España, 2013.

[4] C. R. Batz Saquimux, "Diseño y Construcción de un brazo Robótico," Universidad de San Carlos de Guatemala, Facultad de Ingeniería, Ingeniero en Ciencias y Sistemas, Guatemala, 2005.

[5] J. J. Craig, "Introduction to robotics mechanics and control," Addison-Wesley Publishing Company, 2nd Edition, Boston, 1989.

[6] K. Ogata, Dinamica de sistemas, Prentice Hall, 1987.

[7] C. Evangelista, "Control de sistemas no lineales por modos deslizantes de segundo orden: Aplicación a la conversión de energía eólica," Universidad Nacional de la Plata, Argentina, 2012. 
[8] F. Naranjo, "Sistemas de Control de Estructura Variable con Modo de Deslizamiento," Escuela Politécnica de Universidad de Sao Paulo, Brasil, 1991.

[9] E. A. Chumacero Polanco, "Control tolerante a fallas basado en conceptos de platitud y análisis de intervalos," Maestría en Ciencias Electrónicas, Centro Nacional de Investigación y Desarrollo Tecnológico, Cenidet, Cuernavaca, Morelos, 2010.

[10] Antritter, "On the relation between different flatness based design methods for tracking controllers," American Control Conference, Seattle, USA, 2008.

\section{$7 \quad$ Authors}

Angie J. Valencia $\mathbf{C}$ is with the Mechatronics Engineering Program, Faculty of Engineering, Militar Nueva Granada University, Bogotá, Colombia. Born in Bogotá, Colombia, in 1994. She received the B.S degree in Mechatronics engineering from Nueva Granada Military University, Colombia, in 2015. That year, she joined the DaVinci Group at the Nueva Granada Military University, Colombia, as a researching assistant. Her current research interests include Control Systems, Quadrotor prototype and Robotics.

Óscar F. Avilés S Born in Bogotá, Colombia, in 1967. He received the Engineering degree in Electronics and a Specialist diploma in Electronic Instrumentation from Antonio Nariño University, Colombia, in 1995 and 2002, respectively. Masters degree in Automatic Production Systems from Technological University of Pereira, Colombia, in 2006 and $\mathrm{PhD}$ in Mechanical Engineering from Campinas State University, Brazil. He Currently holds a Professor position in the Department of Mechatronics Engineering in Nueva Granada Military University. He has experience in the areas of Electronic Engineering, with emphasis on electronic instrumentation and control systems, acting mainly on the following topics: robotics, control and biomechatronics.

Mauricio F. Mauledoux. Born in Bogotá, Colombia, in 1982. He received the Engineer degree in Mechatronics engineering from Nueva Granada Militar y University, in 2005. In 2008 as a student of the Masters in Information Technologies and Intelligent Systems in the St. Petersburg State Polytechnic University, Russia, at the automatic and intelligent distributed control department, he was promoted to a $\mathrm{PhD}$. In $2011 \mathrm{He}$ received the PhD degree in Mathematical models, numerical methods and software systems (Red Diploma) from the St. Petersburg State Polytechnic University, Russia. In 2012, he joined the Department of Mechatronic Engineering, at Nueva Granada Military University, Colombia, as an Assistant Professor. His current research interests include Robotics, automatic control, Multi-agent Systems, Smart Grids, and Optimization.

Article submitted 27 July 2017. Published as resubmitted by the authors 30 September 2017. 